\title{
Female First-Year Students Perceptions of Orientation Programs
}

\author{
Beverly G. Dyer, Daniel P. Nadler, and Michael T. Miller
}

Female college students experience unique dimensions to their transition to college. Traditional orientation programming has begun to address the needs of female students, but these efforts have typically not provided the holistic attention deserving of this population. The current report was a case study of 605 female first-year college students, their perceptions of an orientation program based on the CAS Standards, and the differences between Multi-Ethnic and Caucasian females.

Orientation and transitional programs are important components to the undergraduate experience, and often establish the tenor and tone of an individual's entire collegiate experience (Mullendore, 1992). By establishing a "good start" to college, the residual benefits include enhanced retention, a smoother transition to the operational or business related aspect of college, a positive atmosphere among those entering, and key survival skills for those beginning their studies (Twale, 1989; Gardner \& Hansen, 1993). Despite differences in academic content between programs at various institutions, the argument for orientation programs is unchallenged.

An area of concern for many working in orientation is the appropriateness of programs based on different characteristics or traits. A basic question is what should orientation do for whom? Increasingly, orientation experiences are being extended to the classroom and beyond the first semester of enrollment with the idea being that orientation programs and systems need to permeate the student's entire collegiate experience until, figuratively, their roots have taken hold. This trend, however, does not address the foundational issue of stratifying orientation experiences based on some commonality or characteristic (Nadler \& Miller, 1999).

In fact, Nadler and Miller (1999) commented "the culture of the orientation experience needs to be stratified to be supportive of diversity. This culture must also be rich in understanding differences, while simultaneously conveying the expectations of the institution to new students" (p. 26).

One such characteristic deserving of attention is gender. Few programs offer activities or sessions specifically for the unique challenges women face in transitioning to college. In particular, operational and technically focused orientation programs rarely delve into the psychological and social ramifications of being female in the contemporary university.

In 1976 men outnumbered women in college enrollment 5.794 million to 5.191 million. By 1996, however, that number had changed to 6.352 million men compared to

Beverly G. Dyer, Ed.D. is a Visiting Assistant Professor of Higher Education at the University of Alabama. Daniel P. Nadler, Ph.D., is the Associate Dean of Students at Tulane University. Michael T. Miller, Ed.D. is the Associate Dean of the College of Education at San Jose State University in California. 
8.014 million women (Chronicle of Higher Education, 1999). Based on the surge in female student enrollment, the need to examine the female transition to college, as well as their retention, becomes increasingly important.

The current study was subsequently designed to explore the issue of women in orientation. Using a pre-established survey instrument at one case study institution, an orientation program was separated into essential elements and critically examined. The focus of the analysis was purposefully focused on the intent of an orientation program, and what female first-year students drew from the experience.

\section{Background of the Study}

College students have changed in their demographic characteristics as well as their outlook and expectations of the college experience (Loeb, 1994; Johnson \& Miller, 2000). Students entering college at the turn of the century, often referred to as the millenials or Generation Y, have a much broader and deeper base of technology exposure and skills, tend to have name-brand identification, and expect the college experience to be a gateway for a meaningful career (Johnson \& Miller, 2000).

Orientation and transitional programs struggle to offer more than a replication of previous efforts, and through their leaders, attempt to respond to student needs and characteristics. Orientation and transitional programs can be powerful tools for conveying institutional expectations to students while developing friendships and a sense of camaraderie among new students. There tends to be few intra-institutional unifying themes for orientation, however, the Council for the Advancement of Standards (CAS) developed a catalog of 20 purposes of orientation programs. Developed by Senior Student Affairs Administrators (SSAA), these purpose statements offered a framework for thinking about the role and function of orientation (CAS, 1988).

A number of scholars and practitioners have debated and discussed the purposes of orientation and the institutional responsibility to tailor programs to special interest groups or other unique stratifications of students. Although not widely discussed, many institutions do offer specialized programs based on Multi-Ethnicity, such as International student orientation, sessions for African American students, and even programs specifically designed for female students. Little conversation has taken place about the purposes of these programs, and generally institutionally specific purpose statements are used in their justification.

International student orientation activities are among the most clearly defined, as they are often treated as group advising sessions to deal with immigration, visa, and English as a Second Language issues (Ong, 2000). Similarly, but less clearly defined, Multi-Ethnic orientation sessions are often designed to develop a closeness among students as well as provide information about resources available (Nadler \& Miller, 1999). Although largely undocumented, for female students the number of sessions are limited, and often deal with issues such as where to find specific health care resources and personal safety issues. None of these programs, however, have been subject to critical debate, and are only recently becoming of interest to practitioners and scholars alike. Therefore, the current study was designed to document the participation of female 
students in a traditional orientation program, and to identify possible differences in the needs of orientation programs based on Caucasian and Multi-Ethnicity female classification.

\section{Research Procedures}

The current study was a replication of earlier studies of the relevance of the CAS Standards for New Student Orientation at a single case study institution. All participants entering the case study institution in the fall of 1999 were administered a survey that included a demographic section, a request for participants to rate their agreement on a 1to-5 Likert-type scale with each of the CAS Standards, and a section on the participants satisfaction with orientation activities.

The survey instrument was pilot tested and previously used with Cronbach alpha levels at and above .80. The instrument was distributed to all first year students completing the four-day orientation program during one of the final meetings between the orientation team captains and first-year student teams. The majority of these meetings took place in residence halls and the study accepted the assumption that attrition at this point in the orientation program was acceptably low.

The institution of study was a research-focused university with more than 10,000 students located in the Southeastern United States. Admitting students classified as "selective" to "highly selective," a comprehensive, four-day, pre-semester orientation program has consistently been used. The program features many of the activities identified with other multi-day orientation programs, such as a success in test taking, effective use of library resources, team building activities, technical matters related to registration, the bursar, and technology accounts, and a number of "fun" activities such as a hypnotist and a cruise on a local riverboat.

\section{Results}

The survey was returned from 1,204 first-year students at the case study institution. Student respondents were stratified based on gender, and of the 1,204 respondents, 605 were female, approximately 50\%. The 605 females were further stratified based on ethnic background, and of the 605 females responding, 498 were Caucasian (82\%), and the remaining 107 respondents were Multi-Ethnic. The Multi-Ethnic categories included self-identified ethnicities of African-American/Black, American Indian, Asian, Hispanic, Cuban, or Puerto Rican, and other. Of the 605 respondents, 550 identified themselves on the Clark and Trow (1966) subculture classification, based on a brief description of each category. This breakdown included 178 (32\%) students who self-identified with an academic orientation, $273(50 \%)$ a collegiate orientation, $69(12 \%)$ a vocational orientation, and $30(5 \%)$ a non-conformist orientation. These categories of orientation were drawn from the Clark and Trow (1962) classification of college student subcultures, and were presented as a guiding or experimental perspective on female firstyear students.

Respondents, using a 5-point Likert-type scale with 1 representing strongly disagree 
and 5 representing strongly agree, rated 20 items that indicated their level of disagreement or agreement on how well the orientation program met its goals. These 20 items were included on the survey instrument as questions 1 through 20. The top five mean scores, representing the strongest agreement for Caucasian females, ranged from 4.29 to 3.95 while the mean scores, representing the strongest agreement for Multi-Ethnic females ranged from 4.18 to 4.02 . The top five orientation goals indicated by Caucasian females were assisted me in developing positive relationships with other new students (mean $=4.29)$, provided information concerning academic policies, procedures, requirements, and programs $($ mean $=4.12)$, provided appropriate information on personal safety and security (mean $=4.08)$, promoted an awareness of non-classroom opportunities (mean $=4.08)$, and assisted me in understanding the institution's expectations of me $($ mean $=3.95)$. The top five orientation goals indicated by Multi-Ethnic females were provided information concerning academic policies, procedures, requirements, and programs (mean $=4.18$ ), promoted an awareness of non-classroom opportunities (mean $=4.15)$, provided appropriate information on personal safety and security (mean $=4.09$ ), assisted me in developing positive relationships with other new students (mean $=4.09)$, and created an atmosphere that minimized anxiety, promoted positive attitudes, and stimulated an excitement for learning (mean = 4.02). The results indicated that both Caucasian and Multi-Ethnic females strongly agreed that the program provided appropriate information on safety, policies, expectations, and assisted with developing positive relationships with other students.

The five orientation goals reported by the respondents with the least mean agreement for Caucasian females were assisted me in developing positive relationships with institution's faculty (mean $=3.21$ ), assisted me in identifying costs of attending the institution, both in terms of dollars and personal commitment (mean $=3.46)$, assisted me in developing positive relationships with institution's staff (mean $=3.47$ ), provided referrals to qualified advisers and counselors (mean $=3.47$ ), and assisted me in developing positive relationships with individuals from my community (mean $=3.47$ ). The five orientation goals with the least mean agreement for Multi-Ethnic females were assisted me in developing positive relationships with institution's faculty (mean 3.39), assisted me in developing positive relationships with individuals from my community (mean $=3.45$ ), assisted me in developing positive relationships with institution's staff (mean $=3.48)$, provided information about opportunities for self-assessment (mean = 3.57), and assisted me in understanding the mission of the institution (i.e. research, teaching, and service) $($ mean $=3.63)$. The results indicated that the respondents felt that the orientation program was least successful in helping them to develop relationships with the institution's faculty, staff, and the surrounding community.

Respondents, using a 5-point Likert-type scale indicated their agreement that the 17 orientation sessions, activities, personnel, and services items effectively met their needs. The rating scale offered the following responses: $1=$ Poor; $2=$ Fair; $3=$ Average; $4=$ Good; and 5 = Excellent. The top five orientation sessions, activities, personnel, and services indicated by Caucasian females were hypnotist (mean $=4.50)$, residence hall move in $($ mean $=4.31)$, orientation coordinator $($ mean $=4.15)$, overall university services 
(mean $=4.10)$, and overall rating of the program $($ mean $=3.97)$. The top five orientation sessions, activities, personnel, and services indicated by Multi-Ethnic females were hypnotist $($ mean $=4.57)$, orientation coordinator $($ mean $=4.25)$, residence hall move-in (mean $=4.07)$, financial aid $($ mean $=3.98)$, and overall university services $($ mean $=$ 3.96). Results indicated that both Caucasian and Multi-Ethnic females rated the hypnotist as their perceived most effective activity in the orientation program and the orientation coordinator as either good or excellent. The least mean agreement in orientation sessions, activities, personnel, or services reported by Caucasian females were first impressions $($ mean $=3.41)$, campus tour $($ mean $=3.57)$, and being safe in the Big Easy $($ mean $=3.58)$. Multi-Ethnic females least mean agreement in orientation sessions, activities, personnel, or services were campus tour (mean $=3.45$ ), institution's traditions (mean $=3.50$ ), and computing services $($ mean $=3.51)$.

Respondents' ratings of orientation goals were clustered into two groups with mean rating of the items subsequently compared through the use of a T-Test at an alpha level of .05. The groups were those identified as Caucasian and Multi-Ethnic females. For the orientation goals, two significant differences were revealed. The significant differences are indicated in the ratings of the following goals: Multi-Ethnic females agreed significantly more strongly with assisted me in identifying costs of attending institution, both in terms of dollars and personal commitment (mean Multi-Ethnic females $=3.71$; mean Caucasian females 3.46), and provided referrals to qualified advisers and counselors (mean Multi-Ethnic females $=3.81$; mean Caucasian females $=$ 3.46). However, due to the cell size of each category, it is suggested that caution be used in reference to the significance difference.

For the orientation activities and services, six significant differences were revealed in the agreement level of activities and services of the orientation program. The significant differences are indicated in the ratings of the following activities and services: residence hall move-in, overall university services, food services, being safe in the Big Easy, first impressions, and orientation coordinator. Caucasian females agreed significantly more strongly with residence hall move-in (mean Caucasian females 4.31; mean Multi-Ethnic females 4.07), and overall university services (mean Caucasian females Multi-Ethnic 4.10; mean Multi-Ethnic females 3.96) than did Multi-Ethnic females. However, Multi-Ethnic females agreed significantly more strongly with food services (mean Multi-Ethnic females 3.86; mean Caucasian females 3.70), being safe in the Big Easy (mean multi-ethnic females 3.82; mean Caucasian females 3.58), first impressions (mean Multi-Ethnic females 3.75; Caucasian females 3.41), and orientation coordinator (mean Multi-Ethnic females 4.25; mean Caucasian females 4.15). Again, caution should be used regarding the significant differences between Caucasian and Multi-Ethnic females in the sample due to the discrepancy in cell size.

\section{Discussion}

College students face difficult challenges in their transition to college, and despite the rapidity of change in all of society, the separation from home and new found self-reliance, self-dependence, and academic intensity can be traumatic and difficult. 
Transitional programs for first-year students, by design, must deal with the practical and obvious, as well as the future and hidden. For female first-year students, the challenges can be particularly deep and challenging. Issues related to health, sexuality, ambition, and social interactions are all unique challenges and opportunities for female first-year students. By developing uniquely tailored transitional programs, institutions can take a more active approach to prompting student success. The conversation that must occur, however, before these new programs are designed has to do with creating a baseline of knowledge about where programs currently stand. This case study initiates that discussion.

The mean ratings of the purpose of orientation reflect several possible key issues for orientation program leaders to look at as they build programs. First, the safety dimension of orientation and the technical processes of taking care of the business of attending college on campus were strongly agreed with by female first-year students, regardless of ethnicity. This high level of agreement might be an excellent motivator for the review of programs to be sure that they are accurate, meaningful, and to some respect, effective in helping first-year female students to learn about being safe. Second, both groups of female students strongly agreed that learning about the process of taking care of business was an important aspect to orientation. Perhaps, then, orientation coordinators should look at how, and how much attention, is directed to teaching the specific activities and operations of taking care of business on campus. Additional ideas for programming, based on the data, include:

- Orientation is for making friends and getting to know people. This may be part of the reason that residence hall move-in receives such a strong rating. Therefore, make orientation a time to build relationships both between just females, and between males and females.

- Safety is an important issue, and perhaps women see it as more of an issue than males, but either way, females see this as something real. Perhaps this means that the idea of personal safety should be integrated into a wide number of activities, and not just treated as simply another program.

- Students agreed strongly that they were satisfied with their orientation coordinators and the 'fun' activities. Perhaps, then, orientation programs should be designed to allow students to enjoy themselves, integrating various fun activities throughout a program, using these fun programs as opportunities to boost morale.

Overall, the high levels of agreement with both the CAS Standards and the orientation activities suggests that female students do find meaning in orientation. The key for program directors is to capitalize on this stratification, and help female firstyear students get started on a path to success in college. 


\section{References}

Chronicle of Higher Education. (1999). Almanac issue. Washington: Author. Clark, B., \& Trow, M. (1966). The organizational context. In T. Newcomb \& E. Wilson (Eds.), College Peer Groups: Problems and Prospects for Research (pp. 20-24). Chicago: Aldine.

Council for the Advancement of Standards for Student Services/Development Programs. (1988). CAS standards for student services/development programs: Student orientation programs self-assessment guide. Washington: Author.

Gardner, J. N., \& Hansen, D. A. (1993). Perspectives on the future of orientation. In M. L. Upcraft (Ed.). Designing Successful Transitions: A Guide for Orienting Students to College (pp. 183-194). Columbia, SC: Freshman Year Experience.

Johnson, D. B., \& Miller, M. T. (2000). Redesigning transitional programs to meet the needs of generation Y. Journal of College Orientation and Transition, 7(2), 15-20.

Loeb, P. L. (1994). Generation at the crossroads. New Brunswick: Rutgers University.

Mullendore, R. H. (1992). Student based programming in orientation. In D. P. Nadler (Ed.). Orientation Director's Manual (pp. 43-52). Statesboro, GA: National Orientation Director's Association.

Nadler, D. P., \& Miller, M. T. (1999). Designing transitional programs to meet the needs of multi-ethnic first-year students. Journal of College Orientation and Transition, 6(2), 20-27.

Ong, P. (2000). San Jose State University student services for in-country international students. A Plan B thesis, Department of Educational Leadership and Development, San Jose State University, San Jose, CA.

Twale, D. (1989). Social and academic development in freshman orientation: A time frame. NASPA Journal, 27, 160-167. 


\section{Female Ratings of Orientation Goals}

\section{Orientation \\ Goals}

Assisted me in developing positive

relationships with other new students

Provided information concerning

academic policies, procedures,

requirements, and programs

Promoted an awareness of nonclassroom opportunities

Provided appropriate information on personal safety and security

Assisted me in developing familiarity with the physical surroundings

Assisted me in understanding institution's expectations of me

Created an atmosphere that minimized anxiety, promoted positive attitudes, and stimulatedan excitement for learning

Provided an atmosphere and sufficient information that enabled me to make reasoned and well-informed decisions

Explained the process for class scheduling and registration

Provided information and exposure to available institutional services

Assisted me in understanding the purpose(s) of institution (i.e. academic or career)
Caucasian

Mean

$\mathrm{n}=498$

4.299

4.124

4.185

Multi-Ethnic

Mean

$\mathrm{n}=107$

Mean

$\mathrm{n}=605$

4.080

4.154

4.092

4.086

4.093

4.087

3.957

4.010

3.966

3.957

3.854

3.893

4.020

3.847

3.886

3.853

3.802

3.845

3.809

3.798

3.842

3.805

3.792

3.783

3.791 

continuing students

Assisted me in understanding the mission of institution (research, teaching and service)

Provided information about

opportunities for self-assessment attending institution, both in terms of dollars and personal commitment Assisted me in developing positive relationships with individuals from my community relationships with institution's faculty 


\section{Female Ratings of Orientation Activities and Services}

\begin{tabular}{|c|c|c|c|}
\hline $\begin{array}{l}\text { Activities and } \\
\text { Services }\end{array}$ & $\begin{array}{l}\text { Caucasian } \\
\text { Mean } \\
n=498\end{array}$ & $\begin{array}{l}\text { Multi-Ethnic } \\
\text { Mean } \\
n=107\end{array}$ & $\begin{array}{l}\text { Overall } \\
\text { Mean } \\
n=605\end{array}$ \\
\hline Residence Hall Move-In & 4.317 & 4.076 & 4.279 \\
\hline Welcoming Convocation & 3.684 & 3.777 & 3.699 \\
\hline Academic Advisement & 3.738 & 3.813 & 3.750 \\
\hline Registration & 3.827 & 3.876 & 3.835 \\
\hline Overall University Services & 4.105 & 3.962 & 4.082 \\
\hline Accounts Receivable & 3.949 & 3.918 & 3.944 \\
\hline Computing Services & 3.594 & 3.514 & 3.581 \\
\hline Financial Aid & 3.773 & 3.985 & 3.810 \\
\hline Food Services & 3.703 & 3.869 & 3.730 \\
\hline Being Safe in the Big Easy & 3.582 & 3.822 & 3.616 \\
\hline First Impressions & 3.412 & 3.750 & 3.486 \\
\hline Campus Tour & 3.575 & 3.452 & 3.554 \\
\hline Orientation Coordinator & 4.151 & 4.252 & 4.168 \\
\hline Hypnotist & 4.509 & 4.573 & 4.519 \\
\hline River Boat Cruise & 3.738 & 3.609 & 3.721 \\
\hline Institution's Traditions & 3.670 & 3.507 & 3.644 \\
\hline Overall Rating of Program & 3.975 & 3.943 & 3.970 \\
\hline
\end{tabular}

